\title{
Desmatamento, população e desenvolvimento econômico no oeste do Pará nos eixos das Rodovias Santarém-Cuiabá e Transamazônica
}

Objetivou-se, com este trabalho, analisar o processo de crescimento econômico baseado em utilização predatória dos recursos naturais em área de fronteira na Amazônia; avaliar o papel do crescimento populacional no processo de desmatamento e sua influência sobre o crescimento econômico; e o desmatamento como processo de inserção de território de fronteira à ordem social vigente e o resultado do crescimento econômico gerado sobre o desenvolvimento regional à luz das teorias do desenvolvimento econômico de Schumpeter, Celso Furtado, Amartya Sen, Douglass North e Bresser-Pereira.

Palavras-chave: Amazônia; Desmatamento; Desenvolvimento econômico.

\section{Deforestation, population and economic development in western Pará along the Santarém-Cuiabá and Transamazônica Highways}

The objective of this study was to analyze the economic growth process based on predatory use of natural resources in a frontier area in the Amazon; evaluate the role of population growth in the deforestation process and its influence on economic growth; and deforestation as a process of insertion of frontier territory into the prevailing social order and the result of the economic growth generated on regional development in the light of the economic development theories of Schumpeter, Celso Furtado, Amartya Sen, Douglass North and Bresser-Pereira.

Keywords: Amazon; Deforestation; Economic development.

Topic: Desenvolvimento, Sustentabilidade e Meio Ambiente

Reviewed anonymously in the process of blind peer.
Received: 08/03/2019

Approved: 14/06/2019
Marcus Vinicius Reis Souto Bistene Universidade Federal do Oeste do Pará, Brasil

http://lattes.cnpq.br/7954987352159383

mvbistene@gmail.com

Jarsen Luis Castro Guimarães

Universidade Federal do Pará, Brasil

http://lattes.cnpq.br/2403664119078137

http://orcid.org/0000-0003-3102-3099

jarsen@bol.com.br
Referencing this:

BISTENE, M. V. R. S.; GUIMARÃES, J. L. C.. Desmatamento, população e desenvolvimento econômico no oeste do Pará nos eixos das Rodovias Santarém-Cuiabá e Transamazônica. Natural Resources, v.9, n.2, p.1935, 2019. DOI: http://doi.org/10.6008/CBPC2237-9290.2019.002.0003 


\section{INTRODUÇÃO}

A relação entre crescimento econômico, população e desmatamento em áreas de fronteira na Amazônia envolve processos de diferentes categorias - política, economia, ecologia, migração etc. - que se misturam e conformam, absorvendo e sendo absorvidos pelo meio social geograficamente definido onde ocorrem - que pode ser denominado território.

O território geográfico, físico, espacial, ao qual estará submetido este estudo, tem características do que é denominado fronteira. A fronteira é definida em relação aos espaços urbanos, é o que está além do urbano, suburbano e rural-urbano, que tem em si outras realidades, elevado potencial político devido à sua falta de estruturação (VELHO, 1976). Este potencial é realizado na Amazônia através de sua inserção nos mercados globais através da conexão dos fluxos e estoques gigantescos que possui ao espaço global através do crescimento das forças produtivas e à urbanização maciça (BECKER, 1985).

Um destes estoques é o de terras. Milhões de hectares potencialmente agricultáveis, cobertos por floresta tropical densa. É exatamente aí que a fronteira se expressa, principalmente na conversão de áreas florestadas em pastagens ou terras agrícolas. A espacialização das áreas mais dinâmicas em termos de desflorestamento forma áreas funcionais de produção onde a acumulação de capital acontece. Aqui toma forma a proposta de crescimento econômico regional da segunda metade do Século XX na região de interesse. Este padrão de ocupação do solo gera uma estruturação da maximização da renda da terra, tornando o desmatamento fator endógeno de crescimento econômico.

O crescimento econômico regional é um fenômeno que ocorre dentro do sistema econômico nacional, a partir de outros fenômenos que ocorrem em um território definido, subespaço do território nacional. O conceito de território deve ser considerado de forma multidimensional que envolva aspectos espaciais, sociais, econômicos, políticos e culturais.

O crescimento econômico é um fato social, pois é resultado das interações entre as normas, valores e estruturas sociais que vão além dos indivíduos e são regidas por controles também sociais. Para Abbott (1997), não é possível observar fatos sociais isoladamente, sem ligá-los à realidade física em que ocorrem. Daí nasce a importância da territorialidade onde os fatos ocorrem.

O processo de absorção da fronteira pelo Estado a partir de um movimento na direção da urbanização dos espaços de convívio social cria as condições para o crescimento populacional, que por sua vez, causará um aumento da demanda de terras e suprimentos, potencializando o processo de desmatamento.

Neste contexto procura-se compreender o papel de cada um destes vetores - desmatamento, crescimento econômico e crescimento populacional - na dinâmica sócio-política regional, bem como avaliar se há um processo de desenvolvimento econômico sobrejacente em andamento e qual é a natureza deste desenvolvimento, no território multidimensional definido espacialmente ao longo dos eixos das Rodovias BR163 Santarém-Cuiabá e BR-230 Transamazônica. 


\section{METODOLOGIA}

O método principal utilizado neste trabalho será o histórico-dedutivo, devido à sua característica de não se basear em pressupostos simples, mas na observação da realidade. Suas proposições e modelos têm como critério de verdade a coerência com a realidade. Nesta abordagem metodológica, o procedimento básico será a observação de fatos históricos, sua análise e a proposição de modelos baseado neles. Mas o que são fatos, exatamente? Fato é tudo aquilo que é conhecido ou assumido como pertencente ao domínio da realidade. O método se ajusta ao empirismo dos dados e desenvolve hipóteses a partir de observações. Deve ser destacado o seu caráter indutivo, uma vez que tem como objetivo uma visão geral do sistema a partir do teste das hipóteses baseadas em tais fatos observados.

Dificilmente há uma divisão clara entre causas e efeitos em pesquisa social e dada a constante mutação cultural e institucional que ocorre nas estruturas sociais os indivíduos que compõem a sociedade e a transformam são por ela influenciados em seus comportamentos (BRESSER-PEREIRA, 2009). A componente população da região de interesse deste trabalho será responsável por representar o homo economicus, aquele "ser que deseja possuir riqueza, e que é capaz de avaliar a eficácia comparativa dos meios para obter aquele fim. Prediz unicamente aqueles fenômenos do estado social que ocorrem em consequência da busca de riqueza" (MILL, 1974). Tal abstração é possível, segundo Persky (1995), uma vez que "O homem econômico de Mill tem quatro interesses distintos: acumulação, lazer, luxo e procriação".

O território geográfico ou região de interesse deste estudo será conformada pela divisão políticoadministrativa representada por treze municípios do oeste do estado do Pará, por onde passam duas rodovias pensadas e construídas para possibilitar o povoamento e a integração da região com o restante do país, as BR-163 (Santarém-Cuiabá) e a BR-230 (Transamazônica). Território, entretanto, é um conceito que vai além do espaço geográfico que ocupa e com este não deve ser confundido, pois o espaço é a abstração física apropriada por determinado agente, e dá suporte ao surgimento de uma territorialidade através de relações de poder de tal agente sobre aquela parcela apropriada (RAFFESTIN, 1993; ALBAGLI, 2004).

Os territórios são definidos pela forma como ocorrem as interações sociais em seu interior e pelas instituições que regulam tais interações (ABRAMOVAY, 2006). Haesbaert (2004) chega mesmo a afirmar que não há território fora do ambiente social, demarcando, assim, uma posição teórica na qual a imaterialidade do território é ainda mais importante que seu espaço físico.

Subsidiariamente, o método hipotético-dedutivo será utilizado para abordar aquelas questões que exigem hipóteses precisas e quantificáveis, através da formulação de conjecturas que passam por um processo de inferência dedutiva, que testa a predição da ocorrência de fenômenos abrangidos pela referida hipótese (PRODANOV et al., 2013). As relações entre as variáveis população, desmatamento e evolução do Produto Interno Bruto (PIB), que são de natureza numérica, serão analisadas por este prisma metodológico a partir das análises de correlação entre elas.

Os dados utilizados neste trabalho têm origem em levantamentos sistemáticos realizados por instituições públicas afetas aos temas população e Produto Interno Bruto dos municípios (Instituto Brasileiro 
de Geografia e Estatística - IBGE) e desmatamento (Sistema PRODES - Programa de Cálculo do Desflorestamento da Amazônia - do Instituto Nacional de Pesquisas Espaciais - INPE) com metodologias apropriadas para cada um de acordo com as respectivas instituições responsáveis.

A variável população será analisada pela sua historiografia e terá sua componente de evolução numérica analisada em conjunto com a evolução da área desflorestada em cada município ao longo do tempo e também em relação à evolução do PIB municipal. Os resultados gerados por tais análises qualitativas e quantitativas servirão como base para, em contraposição a parâmetros oriundo de cinco teorias do desenvolvimento testar a hipótese de que o desmatamento gera condições para um crescimento econômico tal que reflita em aumento no bem-estar da população regional, o que se denomina desenvolvimento econômico.

\section{DISCUSSÃO TEÓRICA}

\section{População}

Duas vertentes distintas de movimentação populacional podem ser observadas no histórico recente de ocupação da região. Uma delas tem origem no Nordeste brasileiro, foi canalizada pela BR-230 (Transamazônica) e visava dar vazão a uma pressão populacional gerada por grave período de seca naquela região associada a uma forte concentração fundiária e pobreza extrema de parcela significativa da população, especialmente a rural. A migração nordestina do período compreendido entre as décadas de 1970 e 1980 é impulsionada pelo governo federal a partir da publicação do Plano de Integração Nacional - PIN, que tinha como uma de suas propostas basilares "promover a maior integração à economia nacional das regiões compreendidas nas áreas de atuação da SUDENE e da SUDAM" (BRASIL, 1970), ou seja, integrar ao projeto de desenvolvimento nacional suas duas regiões mais pobres.

Esta mesma legislação informa quais seriam os eixos de deslocamento dos nordestinos para a região amazônica: "A primeira etapa do Programa de Integração Nacional será constituída pela construção imediata das rodovias Transamazônica e Cuiabá-Santarém" (BRASIL, 1970). Reservava ainda uma faixa de terras de 10 km de largura em cada lado das estradas para colonização e reforma agrária. A grande Rodovia Transamazônica, a BR-230, assume então o papel de canal de alívio da pressão social pela qual passava a região nordeste naquele momento e as longas faixas de terra 'livres' geravam a expectativa de um futuro mais promissor para dezenas de milhares de famílias paupérrimas, sem-terra e castigadas por um longo período de secas.

Estes migrantes são pessoas descapitalizadas e em busca de um recomeço na vida cujo destino seriam os assentamentos rurais programados: as agrovilas, as agrópolis e as rurópolis. Agrovilas seriam assentamentos construídos pelo governo contendo 48 ou 66 casas cada uma, localizadas a cada $10 \mathrm{~km}$ ao longo do eixo da rodovia e nas vicinais. Teriam como estrutura básica a presença dos órgãos de apoio aos colonos (INCRA, EMATER, Ministério da Agricultura) e um mercado da COBAL - Companhia Brasileira de Alimentação, escola primária e posto médico (SMITH, 1982). 
As agrópolis seriam centros urbanos para até seiscentas famílias, com maior estrutura de equipamentos urbanos. Construídas apenas no eixo da rodovia principal, eram planejadas para implantação a cada $20 \mathrm{~km}$ e contariam com hospital de pequeno porte, comércio, posto policial e escritórios (SMITH, 1982). O mais alto nível hierárquico desta distribuição rural-urbana seriam as Rurópolis, cidades planejadas para 20.000 pessoas, localizadas a cada $140 \mathrm{~km}$ ao longo do eixo principal da estrada e contaria com bancos, administrações de órgãos públicos, hotéis, aeroporto, hospital completo, serviço de telefonia etc. (SMITH, 1982).

Para Camargo (1973), a implantação das urbanidades rurais em três níveis: a Agrovila, a Agrópolis e a Rurópolis, criariam uma hierarquia urbanística funcional de acordo com a infraestrutura social, cultural e econômica e ocasionariam uma estratificação produtiva e administrativa. O governo pretendia instalar 100.000 famílias nos Programas Integrados de Colonização - PICs - Marabá, Altamira e Itaituba. Promessas de fornecimento a cada futuro assentado de serviços médicos, ajuda de custo no valor de seis salários mínimos, dois hectares de roça pronta, créditos bancários, estradas, compra da produção e uma casa na agrovila (PEREIRA, 2014) seduziram milhares de famílias nordestinas a partirem para a Região Amazônica em busca de melhores condições de vida.

Quanto ao processo de migração e ocupação ao longo da BR-163, este ocorreu principalmente com pessoas oriundas da região sul do país, atraídas pelo "mito de terra livre, riquezas minerais e recursos energéticos supostamente inesgotáveis" (COY et al., 2014). O governo brasileiro fomenta a implantação de projetos de colonização, diferentemente da BR-230 onde a meta seria o assentamento de indivíduos semterra. Esta proposta atrai um sem número de pessoas dispostas a assumir o papel de serem os "homens semterra" a ocupar a propalada 'terra sem homens' ou 'vazio populacional' da Amazônia. A diferença principal, porém, residia na capacidade do colono em inverter capital ou ter capacidade de endividamento para receber investimentos subsidiados pelo governo.

O crescimento da monocultura e a limitação do tamanho das propriedades no Sul tornam a oferta amazônica quase irrecusável, uma vez que havia a possibilidade de ocupar largas extensões de terras, em alguns casos o dobro do que se conseguisse desmatar. Desta forma o fluxo de migrantes no sentido sul-norte é bastante intenso nos anos 1970. As dificuldades, porém, fazem com que grande parte destes migrantes de primeiro momento retorne ao sul e nova onda de migração ocorra nos anos 1980, quando o governo brasileiro incentiva a colonização privada no eixo da BR-163.

Apesar de ambas as situações - assentamento humano oriundo do nordeste e colonização oriunda do Sul - apresentarem certos aspectos comuns, tal como a origem do migrante em sistema ecológico diverso da floresta tropical densa amazônica; pouca ou nenhuma preparação para a empreitada que está por vir; desconhecimento da realidade para a qual se dirige, entre outros, existem características sociais e culturais que tornam os migrantes do Nordeste e do Sul extremamente diferentes. Os sulistas vêm de um ambiente onde a falta de terras a serem distribuídas e a limitação do tamanho das 'colônias' a 25 ha, sendo insuficiente, portanto, para redistribuir a filhos e netos dos primeiros colonos cria a pressão necessária para que haja 
grande interesse de parte da população rural em migrar para a Amazônia, onde a oferta de terras é virtualmente ilimitada.

A organização espacial e social das aglomerações humanas, a forma de interpretar o espaço natural à sua volta, a visão de mundo, o nível médio de educação, a capacidade de gestão de recursos é extremamente diferente entre sulistas e nordestinos e geram diferenças marcantes na paisagem das localidades onde se instalam. Esta última característica é marcante devido, principalmente, à orientação da produção agrícola direcionada ao mercado para a colonização da BR-163 e subsistência com comercialização de excedentes para os assentamentos ao longo da BR-230.

A ocupação e uso do solo apresentam duas funções básicas e iguais para os dois grupos: assentamento humano e produção agrícola por conversão da floresta em pastagens ou áreas agricultáveis. Entretanto a espacialidade das ocupações é diferente. A ocupação ao longo da BR-230 (Transamazônica) ocorreu em assentamentos em lotes que variavam seu tamanho entre 50 e $100 \mathrm{ha}$, a colonização das margens da BR-163 acontecia em parcelas de terra muito maiores, chegando a áreas maiores do que 3.000ha (o máximo constitucional da época) a particulares que tivessem projetos agropecuários.

Todas estas semelhanças e diferenças entre os migrantes criam distintos ambientes políticos e econômicos numa escala sub-regional que traz em si um alto grau de complexidade analítica onde princípios de regulação e de desequilíbrio, contingência e determinismo, criação e destruição, ordem e desordem se entrelaçam e disputam espaço e onde níveis de organização e dinâmicas não lineares marcadas por retroações entre esses níveis ocorrem de modo contínuo (MORIN, 2002).

A atual divisão política municipal da área de interesse estudada é fortemente influenciada pelas dinâmicas de migração, assentamento humano e desmatamento que foram levantadas. Tais dinâmicas geram resultados práticos que devem ser analisados através de indicadores, uma vez que existe a necessidade de uma equalização analítica entre municípios com áreas, população, ambiente político e social, entre outros aspectos, bastante distintas.

O indicador do fluxo econômico de uma determinada região - no caso, o município - será o seu Produto Interno Bruto (PIB), que representa a soma dos bens e serviços produzidos em determinado intervalo de tempo. Entretanto o PIB pode ser considerado não apenas um indicador, mas uma variável do sistema, uma vez que não apenas representa algo que acontece endogenamente, mas é ele mesmo um elemento constituinte, estruturante de tal sistema, pois influencia e é influenciado por diversos outros elementos que formam o tecido social. De forma geral a formação populacional baseada em migração rural pressionou sobremaneira a área florestal, pois todos os migrantes, independente de origem enxergavam na floresta uma barreira a ser literalmente derrubada para implantação de uma nova realidade agroambiental.

\section{Desmatamento}

O desmatamento ou desflorestamento é o processo pelo qual áreas historicamente compostas por vegetação florestal têm sua cobertura arbórea arrancada para converter o uso do solo em áreas antropizadas, tanto para fins econômicos (sob a forma de agricultura, pecuária, mineração); infraestruturais 
(estradas, assentamentos humanos, redes de distribuição de energia, etc.) ou para caracterização de posse improdutiva para fins especulativos. O Instituto Nacional de Pesquisas Espaciais (INPE) conceitua desmatamento como "a conversão de áreas de floresta primária por atividades antropogênicas para o desenvolvimento de atividades agropecuárias detectadas por plataformas orbitais" (INPE, 2013).

Denomina-se conversão de uso do solo a retirada de sua cobertura original ou natural, para a implantação de atividades antrópicas modificadoras do ambiente - tanto físico quanto social. No caso específico deste estudo a pecuária e a agricultura são as atividades que predominantemente tomam o lugar da floresta (FEARNSIDE, 1988; MARGULIS, 2003; RIVERO et al., 2009; HARGRAVE et al., 2013). A região analisada apresenta diversidade geomorfológica considerável o que acarreta ocorrência de áreas aptas à agricultura mecanizada em suas porções mais planas e criação de gado bovino nas demais morfologias.

O desmatamento pode ser descrito como um processo, no sentido de que é uma sequência de eventos ordenados no tempo e sua consequência sobre a dinâmica econômica local tende a ser marcante. Pequenos agricultores de subsistência se assentam em áreas onde estradas abertas por madeireiras dão acesso; a madeira é extraída com auxílio destes agricultores que funcionam como mão-de-obra barata; conforme a consolidação da fronteira amadurece, a indústria madeireira de baixa tecnologia é paulatinamente substituída por pecuaristas e no fim do processo estes são substituídos por agricultura de exportação (MARGULIS, 2003).

Dos três agentes de desmatamento apresentados, os primeiros, pequenos agricultores descapitalizados, pioneiros, sobrevivem exclusivamente de 'mineração de nutrientes', e têm na posse precária da terra uma estratégia de ganhos futuros pela valorização desta terra aos olhos dos agentes seguintes: madeireiros e pecuaristas, seja por conta da consolidação da fronteira ou por incorporação de infraestrutura ao local (MARGULIS, 2003).

Um segundo agente do processo de desmatamento pode ser identificado como sendo os madeireiros. A exploração madeireira utiliza os pioneiros como mão-de-obra e suas posses como fonte de matéria-prima para sua indústria em troca da implantação de estradas e alguma remuneração. Após o esgotamento das essências florestais comerciais nas áreas exploradas, estas são deixadas para que o restante do desmatamento seja realizado pelos pioneiros ou são apropriadas pelos terceiros elementos da sequência, os pecuaristas.

A pecuária surge primeiramente com o objetivo de subsistência ou de reserva de capital, em pequenas áreas e não impacta profundamente a economia da fronteira neste primeiro momento. Ao se instalarem os pecuaristas mais capitalizados é que é possível verificar a ocorrência de um maior dinamismo na atividade. O esquema apresentado é uma generalização, havendo diferenças marcantes entre os municípios observados. Como é o caso de Ururará, onde após uma incipiente pecuarização (VEIGA et al., 1991) está havendo uma forte implantação de lavouras cacaueiras. É possível observar também o caso de Santarém onde a partir do ano 2000 a cultura da soja assume protagonismo.

O desmatamento na Amazônia apresenta características bem definidas em sua evolução. O marco inicial é a proximidade de uma área florestada a alguma via de transporte ou fluxo de pessoas - 
historicamente tem início com as vias aquáticas e mais recentemente, a partir da segunda metade do século $\mathrm{XX}$, com a abertura de vias terrestres, tanto estradas oficiais quanto vias secundárias a estas.

As estradas se tornaram o principal determinante do padrão de desmatamento na Amazônia brasileira (SOARES-FILHO, 2005; FEARNSIDE, 2015, SOUZA et al., 2017). A partir do caminho aberto para uma área florestal, ocorre, então, a abertura de área para assentamento humano, agricultura de subsistência, ampliação da área de agricultura, aproveitamento de madeiras nobres, abertura de áreas para pecuária e extensão das vias terrestres existentes até nova área florestal para reinício do ciclo. Poucas e pequenas variações deste caminho podem ser observadas.

Tardin et al. (1980) realizou levantamento baseado em imagens do satélite Landsat e demonstram que em 1978 apenas 1,55\% da Amazônia se encontravam desmatados. Ainda que detalhes metodológicos e instrumentais da pesquisa criem uma tendência a subestimar este valor, ele é significativo como indicador da pequena pressão sobre a floresta em anos anteriores ao horizonte temporal do trabalho.

Considerando que a construção das rodovias foi iniciada no princípio da década de 1970 e que tiveram a conclusão da abertura de seus traçados no biênio 1973-1974, percebe-se a clara e intensa influência das estradas sobre a dinâmica de desmatamento. O desflorestamento, porém, não ocorre sem agentes que o promovam e estes chegam até a região estudada em sua esmagadora maioria pelas vias terrestres recém-abertas.

O Sistema PRODES - Programa de Cálculo do Desflorestamento da Amazônia, do Instituto Nacional de Pesquisas Espaciais, mede as taxas anuais de corte raso desde 1988, para incrementos superiores a 6,25 hectares. A evolução do desmatamento demonstrada por esta metodologia (INPE, 2013) demonstra claramente o impacto da ocupação humana na Amazônia, conforme demonstrado na tabela 1.

Tabela 1: Evolução do desmatamento na Amazônia brasileira.

\begin{tabular}{|l|r|r|r|}
\hline \multicolumn{1}{|c|}{ Período } & Cobertura florestal $\left(\mathbf{K m}^{\mathbf{2}}\right)$ & \multicolumn{1}{c|}{ Cobertura \% } & \multicolumn{1}{c|}{ Perda florestal total desde 1970 $\left.\mathbf{( K m}^{\mathbf{2}}\right)$} \\
\hline Pré-1970 & 4.100 .000 & 100,00 & - \\
\hline 1970 & 4.001 .600 & 97,60 & 98.400 \\
\hline 1978 & 3.955 .870 & 96,50 & 144.130 \\
\hline 1988 & 3.723 .520 & 90,80 & 376.480 \\
\hline 1998 & 3.559 .582 & 86,80 & 540.420 \\
\hline 2008 & 3.373 .252 & 82,30 & 726.748 \\
\hline 2018 & 3.307 .949 & 80,70 & 792.050 \\
\hline
\end{tabular}

A tabela 1 demonstra que até o início da década de 1970 menos de 2,5\% da área florestal da bacia amazônica brasileira havia sido desmatada, números condizentes com o estudo de Tardin et al. (1980). As grandes vias de penetração terrestre na floresta (Rodovias Transamazônica e Cuiabá-Santarém) são abertas exatamente na década de 1970 e têm conclusão em 1978. Neste período, cerca de 1,1\% da floresta é derrubada.

A partir daquele ano o ritmo de desflorestamento aumenta, atingindo 5,7\% no decênio seguinte; $4 \%$ entre 1988 e 1998 e 4,5\% entre 1998 e 2008, uma média de 4,7\% por década. Entre 2008 e 2018 há um declínio destes números, devido a diversos fatores tais como taxas de câmbio desfavoráveis à exportação de commodities e endurecimento na fiscalização ambiental (FEARNSIDE, 2006), políticas fortes de comando e 
controle e incentivo econômico (REYDON, 2011) e intervenções sobre cadeias produtivas de grãos e carne associadas a restrições creditícias e aumento da área instalada de terras protegidas (unidades de conservação e terras indígenas) (NAPSTAD et al., 2014).

Contudo, mesmo apresentando taxas decrescentes, o desmatamento ainda é um processo ativo e alterações em quaisquer das variáveis que o influenciam pode desencadear um caminhamento a outro patamar quantitativo, principalmente se forem alteradas as condições de contorno político-administrativas regionais ou nacionais.

\section{Produto Interno Bruto (PIB)}

O Produto Interno Bruto dos bens representa, pela definição do IBGE (2016). Esta abordagem do PIB permite que se possa exprimi-lo tanto pelo viés da produção, como da despesa quanto da renda. O PIB per capita, também chamado renda média, é o valor do PIB dividido pela população da região analisada. Este valor indica, mesmo que de modo enviesado, a produtividade e ao mesmo tempo a riqueza regional.

O total de serviços produzidos pelas unidades produtoras residentes destinados ao consumo final sendo, portanto, equivalente à soma dos valores adicionados pelas diversas atividades econômicas acrescida dos impostos, líquidos de subsídios, sobre produtos, também é equivalente à soma dos consumos finais de bens e serviços valorados a preço de mercado sendo, também, equivalente à soma das rendas primárias.

\section{As correlações entre população, PIB e desmatamento}

Realizando a análise de correlação entre os dados de evolução anual do PIB e área desmatada nos municípios da região de interesse, no período compreendido entre 2000 e 2012, chega-se a resultados marcantes. Em todos os municípios a correlação entre crescimento do PIB e a área total desflorestada é positiva e muito forte, variando entre 0,79 e 0,98. Estes resultados demonstram que as duas variáveis (PIB e desmatamento) têm um comportamento crescente ao longo do tempo.

A análise de correlação demonstra o comportamento numérico entre as variáveis, porém não indica se há um nexo de causalidade entre elas. Para o caso da correlação entre PIB e desmatamento: o crescimento da área desmatada depende do aumento do PIB ou é o aumento da área desmatada que faz o PIB crescer, numa causalidade direta. Entretanto, é nos municípios com maior área desmatada onde ocorrem os maiores valores de PIB, conforme a figura 1. Apesar da figura mostrar dados apenas para o ano de 2010, o comportamento da curva é semelhante para os demais períodos.

Tabela 2: Matriz de correlações entre as variáveis observadas.

\begin{tabular}{|l|r|r|r|}
\hline \multicolumn{1}{|c|}{ Município } & PIB x Desmatamento & PIB x População & \multicolumn{1}{c|}{ Desmatamento x População } \\
\hline Altamira & 0,8519 & 0,9072 & 0,9448 \\
\hline Aveiro & 0,9802 & 0,2372 & 0,2169 \\
\hline Belterra & 0,9079 & 0,1198 & 0,0244 \\
\hline Brasil Novo & 0,8840 & $-0,2748$ & 0,0982 \\
\hline Itaituba & 0,9876 & 0,3892 & 0,4211 \\
\hline Jacareacanga & 0,8841 & 0,4623 & 0,2596 \\
\hline Medicilândia & 0,7961 & 0,9595 & 0,6898 \\
\hline Novo Progresso & 0,9015 & $-0,2322$ & $-0,2415$ \\
\hline Placas & 0,9554 & 0,9910 & 0,9590 \\
\hline Rurópolis & 0,9784 & 0,9896 & 0,9744 \\
\hline
\end{tabular}




\begin{tabular}{|l|r|r|r|} 
Santarém & 0,9324 & 0,9465 & 0,8137 \\
\hline Trairão & 0,9467 & 0,6581 & 0,7999 \\
\hline Uruará & 0,8987 & $-0,1621$ & 0,0621 \\
\hline
\end{tabular}

Com relação às correlações entre população e desmatamento, há um comportamento diferente. Nos municípios onde a população apresenta alta correlação com o PIB, também apresentará alta correlação com o desmatamento e naqueles com baixa correlação com o PIB apresentará também baixa correlação com o desmatamento.

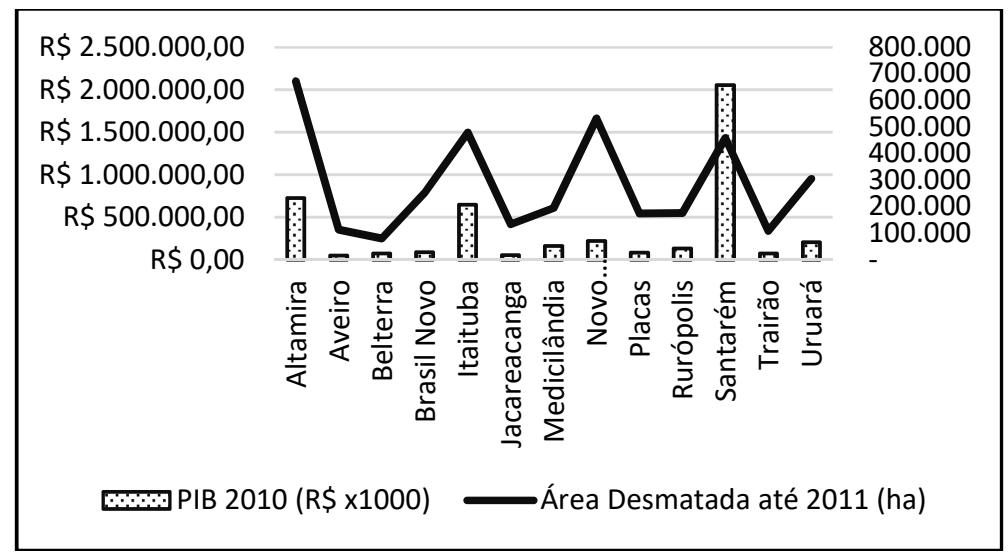

Figura 1: PIB municipal em 2010 e Área total desmatada até 2011.

Estas observações indicam que o modelo de crescimento econômico adotado para a região é intensivo em uso de recursos naturais, onde a floresta é sistematicamente convertida em áreas de expansão das atividades produtivas. A figura 2 demonstra a evolução numérica da população, do PIB e da área total desmatada na região de interesse deste estudo. Enquanto a população teve variação pequena, quase imperceptível na escala apresentada, a área total desflorestada acumulada apresenta um crescimento mais acentuado, indicando que o desmatamento não ocorre por pressão populacional. TRITSCH et al. (2016) demonstra isso ao concluir que as áreas desmatadas são o maior vazio populacional da Amazônia, uma vez que cerca de um terço da área total desmatada na Amazônia inteira é por eles denominada de 'deserto humano desflorestado'.

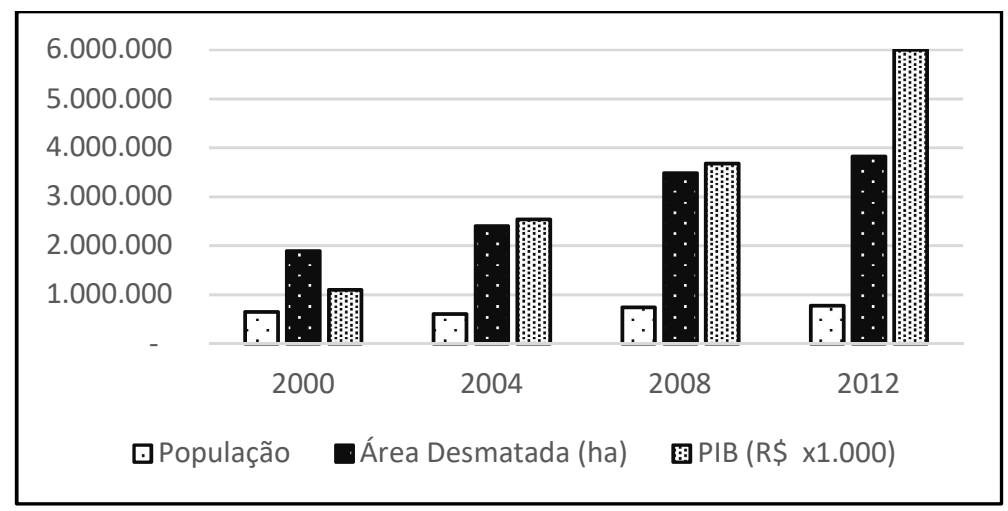

Figura 2: Gráfico comparativo da evolução da população, PIB e área desflorestada ao longo do tempo.

Quando é inserido na análise o crescimento do PIB, verifica-se que este apresenta um comportamento de crescimento muito mais acelerado do que o desmatamento, indicando que existe um ganho de produtividade em relação às áreas desmatadas. Como visto na figura 2, este ganho de 
produtividade não se reflete em melhoria no bem-estar social, tornando assim a percepção do desmatamento muito negativa e a apropriação do valor gerado pelo desmatamento muito concentrada.

\section{Desenvolvimento ou Crescimento Econômico?}

Ao processo ou fenômeno quantitativo da expansão ou incremento de certo número de indicadores econômicos, resultando num aumento de valor de bens finais e serviços produzidos em determinado espaço geográfico, refere-se ao aumento da capacidade produtiva da economia o nome de crescimento econômico. O crescimento econômico é função de muitas variáveis, tais como a disponibilidade de recursos produtivos; produtividade da mão de obra e a poupança nacional, entre outras.

Em termos específicos, crescimento econômico ocorre quando mudanças estruturais e tecnológicas são implantadas em determinada organização social dinâmica e não produzem o aumento da produtividade do trabalho, ou seja, há um crescimento da renda per capita sem que haja, entretanto, um aumento socialmente distribuído de salários e nível de consumo (SCHUMPETER, 1911), mesmo no longo prazo.

Numa breve análise semântica, o termo desenvolvimento é transitivo, ou seja, necessita de uma complementação qualitativa para que indique de forma inequívoca a que se refere. Neste sentido, este trabalho se refere ao desenvolvimento econômico. E esta significação não representa, por si só, uma simplificação, pois existem variadas maneiras de entendê-lo, porém é importante salientar que o simples crescimento da economia não quer dizer necessariamente desenvolvimento - este um fenômeno qualitativo.

Para Schumpeter (1911), o crescimento econômico independe de aspectos populacionais da renda ou riqueza, uma vez que tais variações não geram um fenômeno qualitativamente novo. Para Schumpeter (1911), o desenvolvimento ocorre quando há uma crise, uma mudança que altere a normalidade vigente, deslocando o estado de equilíbrio reinante para outro patamar. Para Schumpeter (1911), o elemento central desta quebra de paradigma social é o empresário inovador, que irá inserir na economia novos produtos, processos, mercados ou mesmo formas organizacionais.

Um conceito básico na teoria de Schumpeter é a 'destruição criativa', processo pelo qual o que era inovador a tempos atrás se torna obsoleto e será substituído por inovações e é o motor propulsor da economia capitalista. Esta passagem geralmente ocorre com aumento de produtividade do capital e do trabalho, pois as novas tecnologias aplicadas ao processo produtivo é que dão impulso ao empresário inovador para realocar-se no mercado.

Furtado $(1961,1981,1992)$ já interpreta o desenvolvimento econômico como um processo histórico que tem a necessidade de encontrar um modelo próprio e apropriado a cada país/região e que seja distinto do modelo rostowiano (ROSTOW, 1960) de desenvolvimento por etapas, típico dos chamados países centrais ou desenvolvidos, cujo modelo baseia-se em seguir etapas de modernização à semelhança daqueles países.

Para Furtado e outros autores ligados à CEPAL (Comissão Econômica para América Latina e Caribe), o ator principal para o processo desenvolvimento é o Estado, uma vez que caberia a ele o papel de diagnosticar e intervir para a solução dos problemas estruturais ligados à produção, emprego e distribuição de renda, nas condições próprias dos países sul americanos. 
As ideias básicas do pensamento de Furtado são fruto da combinação de uma proposta de intervenção estatal na economia de modo keynesiano, com estatização de setores da economia que não criavam interesse imediato junto ao capital privado. Ao mesmo tempo, este mesmo capital privado assumiria o comando das ações junto aos setores mais dinâmicos da economia, gerando ambiente para uma concentração de riqueza endógena que limitaria a fuga de capitais para países estrangeiros.

Assim, o desenvolvimento econômico segundo Furtado, requer um processo intenso de industrialização, que por sua vez, dadas as condições de limitada evolução social, educacional e infraestrutural, geram segmentos que empregam níveis tecnológicos muito distintos, acentuando a concentração de renda (aumentando a desigualdade), o subemprego e a baixa produtividade do trabalho. Um ponto importante em Celso Furtado é a centralidade dada ao fator cultural no processo de desenvolvimento econômico. Para ele somente o crescimento econômico não basta, sendo necessária uma alteração positiva em termos de valores e cultura.

Sen (2000) vai na mesma direção da proposição de Furtado, quando afirma que o desenvolvimento só ocorre a partir do momento em que os indivíduos têm retiradas diante de si as privações à liberdade de evoluir suas capacidades de escolha e de serem agentes e fazerem as ações necessárias ao processo de desenvolvimento - o que caracteriza uma alteração cultural. A liberdade abordada por Amartya Sen diz respeito à possibilidade de o indivíduo alcançar a igualdade de acesso aos recursos - materiais e imateriais para fugir à pobreza (definida pelo modo de vida que o indivíduo considera apropriado segundo seus próprios critérios subjetivos).

O caminho para a liberdade como deseja Amartya Sen é repleto de restrições, concebidas pelos seres humanos com o objetivo de estruturar as relações sociais, políticas e econômicas. Estas restrições podem ser classificadas como instituições (NORTH, 1991). Estas construções permitem diminuir o nível de incerteza nos sistemas sociais através da criação de ordem.

Seguindo o pensamento de Douglass North, existem dois tipos de ordem: a de acesso limitado e a de acesso aberto. Nas sociedades sob ordem de acesso limitado, uma elite detentora de poder (controle) gera um sistema onde os direitos são outorga de privilégios para determinadas classes econômicas e políticas, mas não para todos, com fins de que se mantenha a ordem política, econômica, religiosa, educacional e militar da sociedade, geralmente alcançada pela cooperação entre a elite dominante e a elite política dominante.

É contra este tipo de ordem social que Amartya Sen busca a libertação. O desenvolvimento virá após serem ultrapassadas as barreiras que impedem alterações na estrutura organizacional da sociedade civil consequentemente na dinâmica de geração de riqueza, pois antes disso ocorrer as elites dominantes estruturam o sistema político para limitar a entrada e acesso por quem não é reconhecido por estas elites para atividades que gerem rendas (SALAMA, 2011).

As instituições são as regras que orientam o comportamento social, restringem a ação dos indivíduos, pessoas ou firmas, a padrões desejados socialmente. Podem assumir um caráter formal através de leis, decretos, portarias etc. São o arsenal legal que conforma uma organização social. Também existem as 
instituições informais, regras de comportamento geralmente não escritas que têm aceitação tácita por quem deseja se submeter a um grupo social.

Nas palavras de North (1991), as instituições, "Juntamente com as restrições padrão da economia, definem o conjunto de opções e, portanto, determinam os custos de transação e produção e, portanto, a lucratividade e a viabilidade de se engajar na atividade econômica". Deve ser destacada a questão dos "custos de transação', que nada mais são do que o atrito entre os agentes econômicos e que geram perdas no momento de efetuarem-se as trocas econômicas.

O mercado não opera sob um regime de competição perfeita, isto é, entre os agentes existem diferenças que dão vantagens competitivas de uns sobre outros. Quando os agentes têm que transacionar algum acordo, a incerteza quanto ao posicionamento de cada um deles em relação ao seu poder sobre o mercado, às questões externas à sua produção (externalidade) e à assimetria de informações, gera uma desconfiança mútua que se transforma em custo associado à troca em negociação.

Para diminuir o nível de desconfiança (custo de transação) são utilizados mecanismos de intermediação, notadamente tecnologia e a evolução do quadro institucional, criando, assim, um ambiente de interação evolutiva entre inovações - tecnológicas e de processos - e instituições. O desenvolvimento econômico viria desta característica interativa, através da aceitação social de um paradigma tecnológico que se espraia por todo o tecido social ocasionando mudanças socioeconômicas positivas.

Bresser-Pereira (2014) associa a ideia de desenvolvimento a progresso. Afirma que é um processo histórico de acumulação de capital "incorporando conhecimento técnico que aumenta o padrão de vida da população", ou seja, as mudanças estruturais e tecnológicas que têm lugar em uma organização social e produzem aumento da produtividade do trabalho.

Considerando os aspectos do desenvolvimento elencados, é possível afirmar que a região sob estudo apresenta dinamismo econômico intenso, porém sem contrapartida nos níveis de bem-estar social. Como demonstrativo desta afirmativa podemos comparar a evolução percentual de três indicadores: o IDHM Índice de Desenvolvimento Humano Municipal o PIBpc ou PIB per capita e a evolução populacional dos municípios que compõem a região de interesse entre os anos de 2000 e 2010.

A figura 3 demonstra a discrepância entre as evoluções da população, do IDHM e do PIB per capita entre os anos de 2000 e 2010, em termos percentuais, ou seja, tomando o ano de 2000 como referência. 0 município onde houve o maior aumento do PIB per capita foi Novo Progresso, enquanto a população cresceu 0,71\%, o IDHM passou de 0,466 para 0,673 (aumento de 44,42\%) e o PIBpc teve um acréscimo de 552,45\%. Já o município de pior resultado na evolução do PIBpc foi Placas. A população cresceu 78,69\%, o IDHM passou de 0,390 para 0,552 ou $41,54 \%$ e o PIBpc teve aumento de $155,09 \%$. A média regional foi de mais $15,08 \%$ na população, aumento de $35,86 \%$ no IDHM e crescimento de $288,04 \%$ no PIBpc.

Outra observação importante é que os municípios que tiveram os maiores crescimentos populacionais percentuais, obtiveram os menores resultados em termos de evolução do PIBpc - Altamira, Medicilândia, Placas e Rurópolis - e os municípios com menor crescimento populacional apresentam os melhores resultados em termos de PIB per capita - Novo Progresso, Jacareacanga, Itaituba e Belterra. 




Figura 3: Descompasso entre o crescimento populacional, a evolução do IDHM e crescimento do PIB per capita.

A evolução do IDHM não apresenta grande variabilidade nos resultados entre os municípios, ou seja, a sua evolução não está diretamente correlacionada nem com a população, nem tampouco com a evolução do PIBpc. Tais comportamentos das variáveis indicam uma dissociação entre o crescimento do PIBpc e o bem-estar social.

\section{CONCLUSÕES}

Com relação ao tipo de crescimento econômico observado na região, o processo apresenta um quadro de 'economia estacionária' schumpeteriana, sem desenvolvimento, mas com crescimento baseado em aumento da produtividade pela modernização das tecnologias aplicadas, porém sem o respectivo aumento da produtividade do trabalho, ocasionando saída de grande parte da mão-de-obra do mercado formal de trabalho, assim a taxa de crescimento da economia acompanha o ritmo de acumulação do capital.

Há evolução da renda per capita, porém, com aumento da desigualdade de renda. Tal sistema pode ser classificado como uma ordem de acesso limitado, conforme conceito de North et al. (2009) onde não ocorre um processo de transformação da ordem social e todas as relações ocorrem de forma circular, num sistema fechado.

Diante de todos os argumentos demonstrativos das teorias de desenvolvimento apresentados, não é possível observar alterações sociais que impliquem em desenvolvimento econômico, sob nenhum aspecto, na região estudada. Algumas atividades econômicas demonstram evolução técnica ou adoção de processos produtivos intensos em tecnologia (como a agricultura), porém sem que haja um ganho de produtividade do trabalho que abarque todo o conjunto do espectro econômico regional, confirmando a teoria de que o crescimento econômico que ocorre na região trata-se de ampliação do capital circulante pela modernização dos processos produtivos, porém de forma conservadora e excludente (CANUTO, 2004).

A região sob análise passa por um momento em que os processos produtivos econômicos estão migrando, de atividades típicas de fronteira - extrativismo predatório vegetal e mineral; desflorestamento com fins especulativos da terra, por exemplo - para aqueles presentes em áreas de consolidação da fronteira, de incorporação desta fronteira ao sistema nacional.

A destruição da cobertura florestal ganha, assim, um significado social positivo: a transformação de um espaço literalmente selvagem em território espacial, social e cultural reconhecido pela ordem social 
predominante, conquistado pela via econômica. Neste sentido o próprio domínio da violência na fronteira é lido como típico da fronteira e não da ordem social que a subjuga.

A relação crescimento econômico $x$ desmatamento ocorre em degraus e não de modo contínuo. $O$ incentivo público ao desenvolvimento gera crescimento econômico, que gera desmatamento que permite a geração de mais crescimento econômico. No caso estudado, este caminho circular se dá sem evolução institucional, uma vez que a lógica é apenas a da maximização da função utilidade da terra, sem que sua cobertura florestal original seja valorada no sistema.

O desmatamento entra na conta econômica como um custo de oportunidade da 'domesticação' da fronteira, ação necessária para a implantação de atividades econômicas reconhecidas pela estrutura social que se impõe. Ou seja, a área desmatada, mesmo que improdutiva, tem caráter civilizacional, representa a chegada do progresso com a consequente inserção da região na ordem econômica nacional e internacional.

A grande questão regional não é o crescimento econômico, mas o desenvolvimento. A ineficácia em distribuir socialmente a riqueza produzida tem levado a região a altos índices de desigualdade e concentração de renda, tornando a sociedade local de acesso mais fortemente limitado, ou seja, as componentes econômica e política estão dominadas por grupos fechados que se interoperam e organizam a estrutura social visando seus próprios ganhos. $\mathrm{O}$ acesso de novos atores neste sistema é dificultado e existe uma forte tendência ao aumento da violência não controlada pelo Estado naqueles locais onde os direitos de propriedade da terra são obscuros ou não existem.

A característica de ordem de acesso fechado da sociedade na região estudada maximiza o custo ecológico do crescimento econômico e este é socializado, espraiado pela sociedade, sem que sejam aproveitados os benefícios da destruição do ambiente natural para aumentar o bem-estar geral. Tais características tornam a relação crescimento do PIB x Desmatamento um grande processo de modernização conservadora, acarretando uma 'exclusão pela produtividade', pois os avanços no uso de tecnologias e aumento da produção não se refletem em iguais alterações positivas sobre a estrutura agrária e relações de trabalho.

\section{REFERÊNCIAS}

ABBOTT, A.. Of time and Space: The Contemporary Relevance of the Chicago School. Social Forces, v.75, n.4, p.1149-1182, 1997. DOI: http://doi.org/10.2307/2580667

ABRAMOVAY, R.. Para una teoría de los estudios territoriales. In: MANZANAL, M.; NEIMAN, G.; LATTUADA, $M$.. Desarrollo rural: organizaciones, instituciones y territorios. Buenos Aires: Ciccus, 2006.

ALBAGLI, S.. Território e Territorialidade. In: LAGES, V.; BRAGA, C.; MORELLI, G.; SACHS, I.. Territórios em movimento: cultura e identidade como estratégia de inserção competitiva. Rio de Janeiro: Relume Dumará, 2004.

BECKER, B. K.. Fronteira e urbanização repensadas. Revista Brasileira de Geografia, Rio de Janeiro, v.47, n.3, p.357-371, 1985.
BRASIL. Decreto-Lei n.1.106 de 16 de junho de 1970. Brasília: DOU, 1970.

BRESSER-PEREIRA, L. C.. Desenvolvimento, progresso e crescimento econômico. Lua Nova, São Paulo, v.93, p.33-60, 2014.

BRESSER-PEREIRA, L. C.. Os dois métodos e o núcleo duro da teoria econômica. Revista de Economia Política, v.29, n.2, p.163-190, 2009. DOI: http://doi.org/10.1590/S0101$\underline{31572009000200001}$

CAMARGO, J. G. C.. Urbanismo rural. Brasília: MA, 1973.

CANUTO, A.. Agronegócio: A modernização conservadora que gera exclusão pela produtividade. Nera, v.7, n.5, 2004. 
COY, M.; KLINGLER, M.. Frentes pioneiras em transformação: o eixo da BR-163 e os desafios socioambientais. Territórios \& Fronteiras, Cuiabá, v.7, n.1, p.1-26, 2014.

FEARNSIDE, P. M.. Causas de desmatamento na Amazônia Brasileira. Pará Desenvolvimento, v.23, 1988.

FEARNSIDE, P. M.. Desmatamento na Amazônia: dinâmicas, impactos e controle. Acta Amazonica, v.36, n.3, p.395-400, 2006.

FEARNSIDE, P. M.. Hidrelétricas na Amazônia: impactos ambientais e sociais na tomada de decisões sobre grandes obras. Manaus: EDINPA, v.1, p.1-296, 2015.

FERRARI, A. T.. Metodologia da ciência. 2 ed. Rio de Janeiro: Kennedy, 1974.

FURTADO, C.. Desenvolvimento e subdesenvolvimento. Rio de Janeiro: Fundo de Cultura, 1961.

FURTADO, C.. 0 mito do desenvolvimento econômico. 5 ed. Rio de Janeiro: Paz e Terra, 1981.

FURTADO, C.. Subdesenvolvimento revisitado. Economia e Sociedade, Campinas, v.1, n.1, p.5-19, 1992.

HAESBAERT, R.. O mito da desterritorialização: do fim dos territórios à multiterritorialidade. Rio de Janeiro: Bertrand Brasil, 2009.

HARGRAVE, J.; KIS-KATOS, K.. Economic causes of deforestation in the brazilian amazon: a panel data analysis for the 2000s. Environmental and Resource Economics, v.54, p.471-494, 2013.

IBGE. Instituto Brasileiro de Geografia e Estatística. Produto interno bruto dos municípios: ano de referência 2010. 3 ed. Rio de Janeiro: IBGE, 2016.

INPE. Instituto Nacional de Pesquisas Espaciais. Metodologia para o Cálculo da Taxa Anual de Desmatamento na Amazônia Legal. São José dos Campos: INPE, 2013.

MARGULIS, S.. Causas do desmatamento da Amazônia brasileira. Brasília: 2003.

MILL, J. S.. Da definição de economia política e do método de investigação próprio a ela. In: BENTHAM, S. M.. São Paulo: Abril Cultural, 1974. p.291-315.

MORIN, E.. O Método 1: A natureza da natureza. Porto Alegre: Sulina, 2002.

NAPSTAD, D.; MCGRATH, D.; STICKLER, C.; ALENCAR, A.; AZEVEDO, A.; SWETE, B.; BEZERRA, T.; DIGIANO, M.; SHIMADA, J.; MOTA, G. S.; ARMIJO, E.; CASTELLO, L.; BRANDO, P.; HANSEN, M. C.; MCGRATH-HORN, M.; CARVALHO, O.; HESS, L.. Slowing Amazon deforestation trough public policy and interventions in beef and soy supply chains. Science, v.344, p.1118-1123, 2014.

NORTH, D.. Institutions. Journal of Economic Perspectives, v.5, n.1, p.97-112, 1991.

NORTH, D.; WALLIS, J. J.; WEINGAST, B. R.. Violence and Social Orders. Cambridge: Cambridge University Press, 2009.
PEREIRA, A. R.. Colonização e conflitos na Transamazônica em tempos da ditadura civil-militar brasileira. CLIO: Revista de Pesquisa Histórica, n.31, p.1-17, 2014.

PERSKY, J.. Retrospectives: the ethology of homo economicus. Jornal Economic Perspectives, v.9, n.2, 1995.

PRODANOV, C. C.; FREITAS, E. C.. Metodologia do trabalho científico: métodos e técnicas da pesquisa e do trabalho acadêmico. 2 ed. Novo Hamburgo: FEEVALE, 2013.

RAFFESTIN, C.. Por uma geografia do poder. São Paulo: Ática, 1993.

REYDON, B. P.. O desmatamento da floresta amazônica: causas e soluções. Política Ambiental, Belo Horizonte, v.1, n.8, p.143-155, 2011.

RIVERO, S.; ALMEIDA, O.; ÁVILA, S.; OLIVEIRA, W.. Pecuária e desmatamento: uma análise das principais causas diretas do desmatamento na Amazônia. Nova Economia, Belo Horizonte, v.19, n.1, p.42-66, 2009.

ROSTOW, W. W.. The Stages of Economic Growth: A NonCommunist Manifesto. Cambridge: Cambridge University Press, 1960.

SALAMA, B. M.. Sete Enigmas do Desenvolvimento em Douglass North. In: VIEIRA, O. V.; DIMOULIS, D..

Desenvolvimento e Estado de Direito. São Paulo: Saraiva, 2011. p.21-58.

SANTOS, B. S.. Introdução a uma ciência pós-moderna. Rio de Janeiro: Graal, 1989.

SCHUMPETER, J. A.. The Theory of Economic Development. Oxford: 1911.

SEN, A.. Desenvolvimento como Liberdade. São Paulo: Companhia das Letras, 2000.

SMITH, N. J. H.. Rainforest Corridors: The Transamazon Colonization Scheme. Berkeley: Universty of California Press, 1982.

SOARES-FILHO, B. S.. Cenários de desmatamento para a Amazônia. Estudos Avançados, v.19, n.54, p.137-152, 2005. DOI: http://doi.org/10.1590/S0103-40142005000200008

SOUZA, A. A. A.; PONTES, A. N.; ADAMI, N.; NARVAES, I. S.. A Contribuição das Estradas e o Padrão de Desflorestamento e Degradação da Cobertura Florestal no Sudoeste Paraense. Revista Brasileira de Cartografia, Rio de Janeiro, n.69, p.1833-1846, 2017.

TARDIN, A. T.; LEE, D. C. L.; SANTOS, R. J. R.; ASSIS, O. R.; BARBOSA, M. P. S.; MOREIRA, M. L.; PEREIRA, M. T.; SILVA, D.; SANTOS FILHO, C. P.. Subprojeto Desmatamento. São José dos Campos: INPE, 1980.

TRITSCH, I.; TOURNEAU, F. M.. Population densities and deforestation in the Brazilian Amazon: New insights on the current human settlement patterns. Applied Geography, v.76, p.163-172, 2016. 
VEIGA, J. B.; TOURRAND, J. F.; QUANZ, D.. A pecuária na

fronteira agrícola da Amazônia: o caso do município de Uruará, PA, na região da Transamazônica. Belém: Embrapa, 1991.
VELHO, O. G.. Capitalismo autoritário e campesinato. Rio de Janeiro: Zahar, 1976.

A CBPC - Companhia Brasileira de Produção Científica (CNPJ: 11.221.422/0001-03) detém os direitos materiais desta publicação. Os direitos referem-se à publicação do trabalho em qualquer parte do mundo, incluindo os direitos às renovações, expansões e disseminações da contribuição, bem como outros direitos subsidiários. Todos os trabalhos publicados eletronicamente poderão posteriormente ser publicados em coletâneas impressas sob coordenação da Sustenere Publishing, da Companhia Brasileira de Produção Científica e seus parceiros autorizados. Os (as) autores (as) preservam os direitos autorais, mas não têm permissão para a publicação da contribuição em outro meio, impresso ou digital, em português ou em tradução. 